\title{
Association analysis of $P D E 4 B$ polymorphisms with schizophrenia and smooth pursuit eye movement abnormality in a Korean population
}

\author{
Joon Seol Bae ${ }^{*}$, Byung-Lae Park ${ }^{2 *}$, Hyun Sub Cheong ${ }^{2}$, Jeong-Hyun Kim³ ${ }^{3}$ Jason Yongha \\ $\mathrm{Kim}^{3}$, Suhg Namgoong ${ }^{2,3}$, Ji-On Kim²,3, Chul Soo Park ${ }^{4}$, Bong-Jo Kim ${ }^{4}$, Cheol-Soon Lee ${ }^{4}$, Jae- \\ Won Kim ${ }^{5}$, Woo Hyuk Choi ${ }^{6}$, Tae-Min Shin ${ }^{6}$, Jaeuk Hwang ${ }^{7}$, In Song Koh ${ }^{8}$, Hyoung Doo Shin ${ }^{2,3}$ \\ and Sung-Il $\mathrm{Woo}^{7}$
}

${ }^{1}$ Laboratory of Translational Genomics, Samsung Genome Institute, Samsung Medical Center, Seoul 135-710, Republic of Korea

${ }^{2}$ Department of Genetic Epidemiology, SNP Genetics, Inc., Sogang University, Seoul 121-742, Republic of Korea

${ }^{3}$ Laboratory of Genomic Diversity, Department of Life Science, Sogang University, Seoul 121-742, Republic of Korea

${ }^{4}$ Department of Psychiatry, College of Medicine, Gyeongsang National University, Jinju, Gyeongsang Nam Do, 660-751, Republic of Korea

${ }^{5}$ Division of Life Science, Research Institute of Life Science, Gyeongsang National University, Jinju, Gyeongsang Nam Do, 660-751, Republic of Korea

${ }^{6}$ Department of Biomedical Engineering, Yonsei University, Wonju, Gangwon 220-710, Republic of Korea

${ }^{7}$ Department of Psychiatry, Soonchunhyang University Hospital, Seoul, 420-767, Republic of Korea

${ }^{8}$ Department of Physiology, College of Medicine, Hanyang University, Seoul, Republic of Korea

\begin{abstract}
Schizophrenia is a debilitating mental disorder with a high heritability rate. Located on chromosome 1p31.3, the human cAMP-specific 3',5'-cyclic phosphodiesterase $4 B(P D E 4 B)$ gene has been considered as an important candidate gene for the risk of schizophrenia. Several genetic association studies reported the association between $P D E 4 B$ polymorphisms and the risk of schizophrenia in Caucasian, African American, Indian, and Japanese populations. The aim of this study is to examine the association of $P D E 4 B$ variations with schizophrenia and smooth pursuit eye movement (SPEM) abnormality in a Korean population. A case-control association analysis was carried out by comparing the genotype distribution of eight $P D E 4 B$ polymorphisms between 457 schizophrenia patients and 386 normal healthy subjects. Differences in the frequency distribution of $P D E 4 B$ single-nucleotide polymorphisms (SNPs) and haplotypes were analyzed by logistic regression analyses controlling for age as a covariate. Statistical analyses revealed nominal significant associations of $r s 1040716, r s 472952$, $r s 1321177$, and $r s 2144719$ with the risk of schizophrenia $(p=0.02 \sim 0.05)$. The $r s 11208756$ polymorphism showed a nominal significant association with SPEM abnormality $(p=0.05)$. In a meta-analysis with Japanese and Korean populations, three SNPs (rs472952, rs1040716, and rs2180335) revealed significant associations with schizophrenia (meta- $p$ value $=0.0038 \sim 0.019$ ). Our results support previously reported association of $P D E 4 B$ variations with schizophrenia in other populations. The findings in this study add a new evidence for the involvement of $P D E 4 B$ gene in schizophrenia etiology.
\end{abstract}

Key words: $P D E 4 B$ - Schizophrenia - Single-nucleotide polymorphism - SPEM abnormality - Genetic factor

Abbreviations: LD, linkage disequilibrium; PDE, phosphordiesterase; SNP, single-nucleotide polymorphism; SPEM, smooth pursuit eye movement.

Correspondence to: Sung-Il Woo, Department of Neuropsychiatry, Soonchunhyang University Hospital, 657, Hannam-dong, Yongsangu, Seoul 140-743, Republic of Korea

E-mail: siwoo@hosp.sch.ac.kr
Hyoung Doo Shin, Department of Life Science, Sogang University, Seoul; Department of Genetic Epidemiology, SNP Genetics, Inc., Seoul, 121-742, Republic of Korea

E-mail: hdshin@sogang.ac.kr

* Both authors contributed equally to this manuscript. 


\section{Introduction}

Schizophrenia is a debilitating mental disease affecting $1 \%$ of the general population in the world. The development of schizophrenia has been known to be highly heritable as shown by twin studies (Cardno and Gottesman 2000). Through previous studies about genetic variations associated with schizophrenia (Kirov et al. 2004; Li et al. 2006; Silberberg et al. 2006; Numata et al. 2008; Chen et al. 2009; Lepagnol-Bestel et al. 2010), disrupted in schizophrenia 1 (DISC1), neuregulin 1 (NRG1) and dystrobrevin binding protein 1 (DTNBP1) have emerged as considerable causal genes. Among them DISC1 was reported originally as a risk factor for major mental illness by a study of a large Scottish family in which a balanced translocation between chromosomes 1 and 11 cosegregates with schizophrenia, bipolar disorder, and recurrent major depression (Millar et al. 2000). The outcome of the translocation was direct simultaneous disruption of DISC1, a conventional protein coding gene, and DISC2, an antisense noncoding RNA gene on chromosome 1 (Millar et al. 2000).

Disruption of the phosphordiesterase $4 B$ (PDE4B) gene in two cousins, one with schizophrenia and the other psychosis, by different chromosomal translocation at $1 \mathrm{p} 31.2$ locus was reported later and PDE4B interacted dynamically with DISC1, possibly modulating cAMP levels in a protein kinase A phosphorylation-dependent manner (Davis et al. 1995; Millar et al. 2005). Thereafter evidences of genetic association between $P D E 4 B$ polymorphisms and schizophrenia from different ethnicity such as Caucasian, African American, Indian, and Japanese populations were reported (Fatemi et al. 2008; Numata et al. 2008).

The class I PDE super-family in mammals is consisted of 11 members, each of them with distinct kinetic and regulatory properties. Among them, PDE4, 7 and 8 specifically hydrolyze cAMP. PDE1, 2, 3, 10 and 11 hydrolyze both cAMP and GMP. PDE5, 6 and 9 hydrolyze just cGMP. PDE4s are highly conserved over evolution, being found in Drosophila melanogaster and Caenorhabditis elegans; isoforms in man and mouse exhibit near identical sequences (Houslay 2010). And the mutation of dunce gene encoding PDE in Drosophila melanogaster can attribute to increase of cAMP level, and it was related with deficits in olfactory learning and behavioral defects (Davis et al. 1995).

Four genes $(P D E 4 A / B / C / D)$ encode over 20 distinct PDE4 isoforms as a result of mRNA splicing and the use of distinct promoters (Houslay 2010). The human PDE4B gene on the $1 \mathrm{p} 31.3$ region is comprised of 17 exons spanning 580kb (Houslay and Adams 2003). PDE4B gene was suggested as a risk factor for schizophrenia because PDE is a key molecule to inactivate cAMP which is involved in learning, memory, and mood (Davis et al. 1995; Millar et al. 2005) and mediates cAMP signaling by interaction with
DISC1 (Millar et al. 2005). Taken together, PDE4B gene can be a considerable causal gene involved in schizophrenia pathogenesis with genetic, biochemical and pharmacological evidences as described above. In this study, we performed association analysis of $P D E 4 B$ variations with schizophrenia and smooth pursuit eye movement (SPEM) abnormality in a Korean population.

\section{Materials and Methods}

\section{Subjects}

A total of 843 subjects were included in the study. Schizophrenia patients $(n=457)$ were recruited from Jinju Mental Hospital, Soonyoung Hospital, Hadong Wooridle Hospital (Gyeongsang Nam Do, Korea), Seoul National Hospital (Seoul, Korea) and Keyo Hospital (Kyunggi-Do, Korea) and unrelated healthy controls $(n=386)$ were recruited from Hangang Sacred Heart Hospital and the Center for Health Promotion in Seoul National University Hospital (Seoul, Korea). The protocols were approved by Institutional Review Board of the each hospital, and the experiments were undertaken with the understanding and written informed consent of each subject. Trained psychiatrists diagnosed schizophrenia based on the criteria set forth by the Diagnostic Statistical Manual of Mental Disorders IV (DSM-IV) (Association 2000). Patients with complicating diagnoses of mental retardation, organic brain damage, drug or alcohol abuse, neurological disorders, autoimmune disorders, and low comprehension skills were excluded from the study.

\section{Measurement of smooth pursuit eye movement (SPEM)}

A total of 113 schizophrenia patients who were able to understand the procedure of the experiment underwent an eye tracking task as described previously (Bae et al. 2012). The setting for the SPEM task was a darkened quiet room, wherein the schizophrenia patients were instructed to sit in front of a 19-in. computer monitor at a distance of $40 \mathrm{~cm}$ and asked to closely observe a moving target spot $(0.8 \times 1 \mathrm{~cm})$ which appeared at the center of the computer monitor screen for $0.5 \mathrm{~s}$ and then moved horizontally back and forth in an $18.2^{\circ}$ of visual arc to each side of the screen at a constant speed of $28.2^{\circ}$ per second. Electrophysiological analog signals of SPEM were amplified and sampled at $400 \mathrm{~Hz}$ and converted into digitized files using BiopacMP150 (BIOPAC Systems, Goleta, CA, USA). During the challenge, $15 \mathrm{~s}$ of measurement period was sampled at $4 \mathrm{~Hz}$ and passed through a 2-Hz low-pass filter. The electro-oculogram (EOG) data underwent fast Fourier transformation, and the natural logarithmic value 
of signal/noise (Ln S/N ratio) was calculated from analysis of the power spectrum curves. With an $\mathrm{Ln} \mathrm{S} / \mathrm{N}$ ratio of 3.97, subjects were categorized into 'good' and 'poor' performers according to their SPEM function.

\section{Selection and genotyping of PDE4B polymorphisms}

The peripheral blood leukocyte samples from 843 samples were collected in tubes containing sodium ethylenediaminetetraacetic acid, and then genomic DNA was obtained by the QIAamp blood extraction kit (QIAgen, Valencia, USA). Eight single-nucleotide polymorphisms (SNPs; rs11208756, rs6700403, rs599381, rs1040716, rs2180335, rs472952, rs1321177, and rs2144719) in PDE4B were selected from polymorphisms in the literature and genotyped for the present study (Fatemi et al. 2008; Numata et al. 2008; Holliday et al. 2009). Commercially available pre-designed TaqMan probes and primers (Applied Biosystems, Foster City, CA, USA) were used in genotyping (see Table S1 in Supplementary Material). Haplotypes were inferred from the genotyped SNPs using the PHASE algorithm ver. 2.0 (Stephens et al. 2001), and those with frequency of over 0.05 were included in the association analysis.

\section{Statistical analysis}

We examined Lewontin's D' $\left(\left|D^{\prime}\right|\right)$ and linkage disequilibrium (LD) coefficient $r 2$ between all pairs of biallelic loci using Haploview algorithm (Barrett et al. 2005). Odds ratio (95\% confidence interval) and corresponding $p$-values were calculated using logistic model controlling for age as a covariate. $\mathrm{Ln} \mathrm{S} / \mathrm{N}$ ratio was calculated from analysis of the power spectrum curves, and results were used in logistic analysis of SPEM abnormality. Statistical power of single associations was determined using the Power for Genetic Association Analyses (PGA) software (Menashe et al. 2008). The average statistical power was $74.6 \%$. The meta-analysis was conducted by using PLINK (http://pngu.mgh.harvard. edu/ purcell/plink/metaanal.shtml). After $p$-values and odd ratios were obtained from literatures, meta- $p$ values were calculated according to PLINK's protocol. If odds ratios were not included in literatures, we used a tool in MedCalc (http://www.medcalc.org/calc/odds_ratio.php) to calculate odds ratios from each number of genotypes in cases and controls.

\section{Results}

\section{Characteristics of study subjects}

In this study, we explored a genetic association between $P D E 4 B$ polymorphisms and the risk of schizophrenia with 843 subjects divided into 457 schizophrenia patients and 386 healthy controls. The summary of clinical profiles in this study was listed in Table 1 . In some of schizophrenia patients $(n=113)$, we measured Ln S/N ratios of SPEM abnormality by an eye tracking task. A significant difference of $\mathrm{Ln} \mathrm{S} / \mathrm{N}$ between good and poor groups $(p<0.001)$ was observed (Table 1).

\section{Genotyping of PDE4B polymorphisms}

Total eight polymorphisms (rs11208756, rs6700403, rs599381, rs1040716, rs2180335, rs472952, rs1321177, and rs2144719) in intronic region of $P D E 4 B$ gene were selected from International HapMap database and successfully genotyped in a total of 843 subjects (Figure 1, Table S2 in Supplementary Material). With an average call rate of over 95\%, all eight $P D E 4 B$ SNPs were successfully genotyped in a total 843 subjects. None of variants revealed significant deviations from Hardy-Weinberg equilibrium (Table S2). Pair-wise comparison of the genotyped SNPs revealed 3 tight LD blocks (Figure IB). Seven major haplotypes with frequency over 0.05 were inferred from these LD blocks (Figure IC). Among these constructed haplotypes, only two haplotpyes (BL1_ht2 and BL3_ht3) were used further association analysis because other five haplotypes $\left(B L 1 \_h t 1\right.$, $B L \_h t 3, B L 2 \_h t 1, B L 2 \_h t 2$, and BL3_ht1) were equivalent to some SNPs.

Table 1. Summary of clinical profiles

\begin{tabular}{|c|c|c|c|c|}
\hline Parameters & & Schizophrenia patients & & Healthy control \\
\hline Number of subjects & & 457 & & 386 \\
\hline Age (Range) & & $44.78(23-76)$ & & $54.72(28-79)$ \\
\hline Sex $(n$, male/female $)$ & & $255 / 202$ & & $217 / 169$ \\
\hline SPEM measurement in patients & Subjects $(\mathrm{N})$ & Age (year) & Ln S/N ratio of SPEM ${ }^{*}$ & \\
\hline Poor $(<3.97)$ & 64 & $46.2 \pm 9.3$ & $3.26 \pm 0.59$ & \\
\hline Good ( $\geq 3.97)$ & 49 & $44.3 \pm 9.9$ & $4.30 \pm 0.28$ & \\
\hline
\end{tabular}

Values are mean \pm SEM. Ln S/N, natural logarithmic values of the signal/noise; ${ }^{\star}$ significant difference between poor and good SPEM (smooth pursuit eye movement) groups $(p<0.001)$. 
A

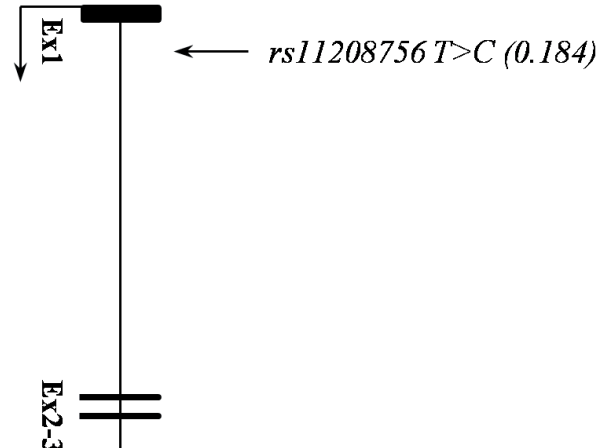

B

\begin{tabular}{|c|c|c|c|c|c|c|c|c|c|c|c|c|}
\hline \multicolumn{4}{|c|}{ BL1 } & \multicolumn{4}{|c|}{ BL2 } & \multicolumn{5}{|c|}{ BL3 } \\
\hline Hap. & $\bar{z}$ & $\sum_{i}$ & Freq. & Hap. & $\sum_{i}^{n}$ & $\sum_{2}^{+}$ & Freq. & Hap. & $\sum_{3}^{n}$ & $\sum_{3}^{0}$ & $\hat{\S}$ & Freq. \\
\hline htl & $\mathrm{C}$ & $\mathrm{G}$ & 0.477 & ht 1 & $\mathrm{~T}$ & $\mathrm{G}$ & 0.787 & ht 1 & $\mathrm{G}$ & $\mathrm{T}$ & $\mathrm{T}$ & 0.790 \\
\hline $\mathrm{ht} 2$ & $\mathrm{~T}$ & $\mathrm{G}$ & 0.436 & ht 2 & A & A & 0.198 & ht 2 & A & $\mathrm{T}$ & $\mathrm{T}$ & 0.124 \\
\hline ht3 & $\mathrm{T}$ & A & 0.086 & ht3 & A & G & 0.013 & ht3 & A & $\mathrm{G}$ & $\mathrm{G}$ & 0.066 \\
\hline ht4 & $\mathrm{C}$ & A & 0.0006 & ht4 & $\mathrm{T}$ & A & 0.002 & $\mathrm{ht} 4$ & A & $\mathrm{G}$ & $\mathrm{T}$ & 0.019 \\
\hline
\end{tabular}

C

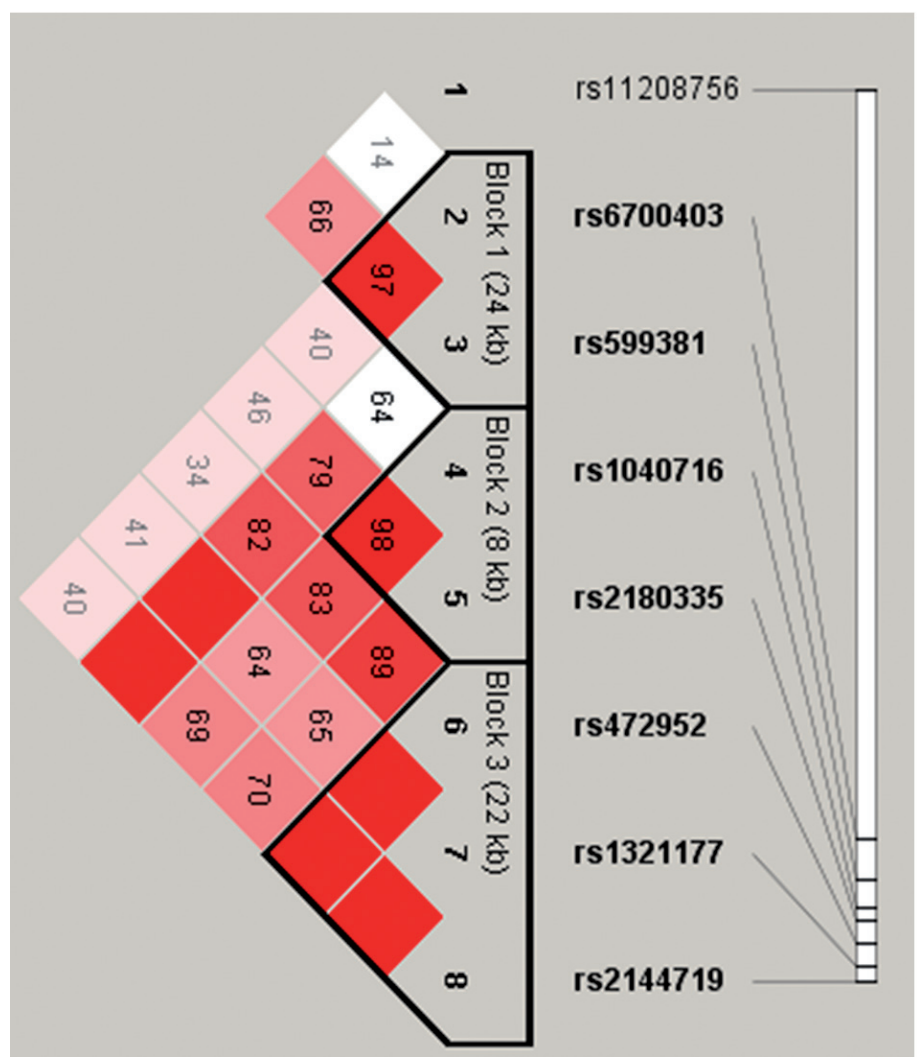

Figure 1. Physical map, Linkage disequilibrium (LD), and haplotypes of the PDE4B gene. A. Schematic gene map and singlenucleotide polymorphisms (SNPs) of $P D E 4 B$ on chromosome 1p31.3. Black blocks represent coding exons. The first base of translation site was denoted as nucleotide +1. B. Haplotypes of PDE4B. List of SNP1 7: rs6700403, rs599381, rs1040716, rs2180335, rs472952, rs1321177, rs2144719, respectively. C. LD coefficient (|D'|) among PDE4B SNPs in a Korean population. Numbers in blocks represent values of multi-allelic D'. Shades of red/pink indicate $\log$ of the Odds (LOD) $\geq 2$, whereas white blocks indicate LOD $<2\left(D^{\prime}<1\right)$. 
Association analysis of PDE4B variations with schizophrenia and SPEM abnormality

Allele frequencies of 8 SNPs and 2 haplotypes were compared between schizophrenia patients and healthy controls using logistic analysis controlling age as covariate. The results revealed that 4 SNPs (rs1040716, rs472952, rs1321177, and $r s 2144719)$ were nominally associated with a risk of schizophrenia $(p=0.02 \sim 0.05$, odds ratio $=0.62 \sim 0.72)$ (Table 2). Since SPEM has been reported to be one of the most consistency neurophysiologic abnormalities associated with schizophrenia, we also conducted case-control association analysis among schizophrenia patients who were classified into poor and good SPEM performers at an $\mathrm{Ln} \mathrm{S} / \mathrm{N}$ ratio value of 3.97. In the analysis, $r$ s 11208756 showed a nominal association with SPEM abnormality $(p=0.05$, odds ratio $=$ 0.48) (Table 3).

Meta-analysis of PDE4B polymorphisms with schizophrenia

We conducted meta-analysis and summarized the outcome in Table 4 comparing our current results with other studies. The combined analysis suggested that three polymorphisms ( $r$ 1040716, rs2180335, and rs472952) in PDE4B gene are risk factors for schizophrenia in Japanese and Korean populations (meta- $p$ value $=0.0038 \sim 0.019$ ). The $r s 472952$ showed the strongest association for schizophrenia in the two populations $($ meta $-p$ value $=0.0038$, odds ratio $=0.71)($ Table 4$)$.

Table 2. Association analysis of $P D E 4 B$ polymorphisms with the risk of schizophrenia

\begin{tabular}{|c|c|c|c|c|c|c|c|c|c|}
\hline \multirow{2}{*}{ SNP name } & \multicolumn{2}{|l|}{ MAF } & \multicolumn{2}{|c|}{ Co-dominant } & \multicolumn{2}{|l|}{ Dominant } & \multicolumn{2}{|l|}{ Recessive } & \multirow{2}{*}{$\begin{array}{c}\text { Statistical } \\
\text { power }^{\dagger}\end{array}$} \\
\hline & Schizophrenia & Control & OR (95\% CI) & $p$ & OR (95\% CI) & $p$ & OR (95\% CI) & $p$ & \\
\hline rs11208756 & 0.180 & 0.188 & $0.93(0.71-1.24)$ & 0.64 & $0.89(0.64-1.24)$ & 0.48 & $1.18(0.51-2.72)$ & 0.71 & 80.593 \\
\hline rs6700403 & 0.499 & 0.453 & $1.24(0.99-1.55)$ & 0.06 & $1.34(0.95-1.91)$ & 0.10 & $1.32(0.90-1.92)$ & 0.15 & 93.114 \\
\hline rs599381 & 0.080 & 0.094 & $0.98(0.67-1.44)$ & 0.93 & $0.99(0.65-1.50)$ & 0.95 & $0.91(0.18-4.70)$ & 0.91 & 57.277 \\
\hline rs1040716 & & & $0.77(0.59-1.01)$ & & $0.72(0.52-0.99)$ & & $0.81(0.37-1.74)$ & 0.58 & \\
\hline rs 2180335 & 0.193 & 0.208 & $0.82(0.62-1.09)$ & 0.17 & $0.78(0.56-1.07)$ & 0.12 & $0.96(0.42-2.19)$ & 0.91 & 83.212 \\
\hline$r s 472952$ & 0.198 & 0.223 & $0.72(0.55-0.96)$ & 0.02 & $0.73(0.53-1.00)$ & 0.05 & $0.47(0.20-1.13)$ & 0.09 & 84.843 \\
\hline rs1321177 & 0.072 & 0.102 & $0.64(0.43-0.95)$ & 0.03 & $0.64(0.42-0.97)$ & 0.04 & $0.24(0.03-2.32)$ & 0.22 & 60.246 \\
\hline$r s 2144719$ & 0.054 & 0.083 & $0.62(0.40-0.96)$ & 0.03 & $0.62(0.39-0.99)$ & 0.04 & $0.24(0.03-2.30)$ & 0.22 & 52.802 \\
\hline$B L 1 \_h t 2$ & 0.423 & 0.451 & $0.83(0.67-1.04)$ & 0.10 & $0.84(0.60-1.18)$ & 0.31 & $0.70(0.47-1.04)$ & 0.08 & - \\
\hline BL3_ht2 & 0.125 & 0.122 & $0.86(0.61-1.20)$ & 0.37 & $0.85(0.59-1.23)$ & 0.40 & $0.73(0.17-3.07)$ & 0.67 & - \\
\hline
\end{tabular}

Logistic regression analyses was used to calculate odds ratios (95\% confidential interval) controlling for age (continuous value) as a covariate. SNP, single-nucleotide polymorphism; MAF, minor allele frequency; OR, odds ratio; $\mathrm{CI}$, confidence interval; ${ }^{\dagger}$ statistical power was calculated by the Power for Genetic Association Analyses (PGA) software. Bold values indicate significant differences $(p<0.05)$.

Table 3. Association analysis of PDE4B polymorphisms with SPEM abnormality in schizophrenia patients

\begin{tabular}{|c|c|c|c|c|c|c|c|c|}
\hline \multirow{2}{*}{ SNP name } & \multicolumn{2}{|c|}{ MAF } & \multicolumn{2}{|c|}{ Co-dominant } & \multicolumn{2}{|l|}{ Dominant } & \multicolumn{2}{|l|}{ Recessive } \\
\hline & Good SPEM & Poor SPEM & OR (95\% CI) & $p$ & OR (95\% CI) & $p$ & OR (95\% CI) & $p$ \\
\hline rs11208756 & 0.104 & 0.219 & $0.48(0.23-0.98)$ & 0.05 & $0.44(0.19-1.02)$ & 0.06 & $0.25(0.03-2.53)$ & 0.24 \\
\hline rs6700403 & 0.537 & 0.447 & $1.42(0.84-2.39)$ & 0.19 & $2.56(1.08-6.04)$ & 0.03 & $1.00(0.43-2.31)$ & 1.00 \\
\hline rs599381 & 0.060 & 0.070 & $0.84(0.31-2.28)$ & 0.73 & $0.93(0.31-2.81)$ & 0.90 & - & - \\
\hline$r s 1040716$ & 0.197 & 0.143 & $1.63(0.78-3.41)$ & 0.19 & $1.79(0.81-3.95)$ & 0.15 & $0.92(0.06-15.40)$ & 0.96 \\
\hline rs 2180335 & 0.194 & 0.143 & $1.65(0.79-3.45)$ & 0.18 & $1.81(0.82-4.01)$ & 0.14 & $0.93(0.06-15.30)$ & 0.96 \\
\hline$r s 472952$ & 0.187 & 0.158 & $1.39(0.69-2.81)$ & 0.36 & $1.62(0.74-3.58)$ & 0.23 & $0.54(0.05-6.33)$ & 0.62 \\
\hline rs1321177 & 0.074 & 0.063 & $1.48(0.50-4.36)$ & 0.48 & $1.48(0.50-4.36)$ & 0.48 & -- & -- \\
\hline$r s 2144719$ & 0.059 & 0.053 & $1.40(0.44-4.45)$ & 0.57 & $1.40(0.44-4.45)$ & 0.57 & -- & -- \\
\hline$B L 1 \_h t 2$ & 0.403 & 0.482 & $0.73(0.43-1.24)$ & 0.24 & $0.92(0.42-2.01)$ & 0.83 & $0.41(0.16-1.08)$ & 0.07 \\
\hline BL3_ht2 & 0.112 & 0.096 & $1.23(0.53-2.89)$ & 0.63 & $1.16(0.47-2.84)$ & 0.75 & -- & -- \\
\hline
\end{tabular}

SPEM, smooth pursuit eye movement; SNP, single-nucleotide polymorphism; MAF, minor allele frequency; OR, odds ratio; CI, confidence interval. Bold values indicate significant differences $(\mathrm{p}<0.05)$. 
Table 4. Comparison and meta-analysis of genetic effect of $P D E 4 B$ polymorphisms with schizophrenia in previous studies

\begin{tabular}{|c|c|c|c|c|c|c|c|c|c|c|}
\hline \multirow[t]{2}{*}{ Population } & \multirow{2}{*}{$\begin{array}{c}\text { Sample } \\
\text { (case/control) }\end{array}$} & \multicolumn{8}{|c|}{$\begin{array}{c}p \text {-value } \\
\text { [Odds ratio] }\end{array}$} & \multirow[t]{2}{*}{ Reference } \\
\hline & & rs11208756 & rs6700403 & rs599381 & rs1040716 & rs 2180335 & rs472952 & rs1321177 & $r s 2144719$ & \\
\hline Caucasian & $644 / 604$ & - & - & 0.30 & 0.0031 & - & - & 0.0004 & 0.0006 & $\begin{array}{l}\text { Fatemi et } \\
\text { al. (2008) }\end{array}$ \\
\hline $\begin{array}{l}\text { African } \\
\text { American }\end{array}$ & $234 / 604$ & - & - & 0.005 & 0.0087 & - & - & 0.51 & 0.47 & $\begin{array}{l}\text { Fatemi et } \\
\text { al. (2008) }\end{array}$ \\
\hline India & 124 families & 0.003 & 0.008 & - & - & - & - & 0.046 & - & $\begin{array}{l}\text { Holliday et } \\
\text { al. (2009) }\end{array}$ \\
\hline Japanese & $444 / 452$ & - & - & $\begin{array}{c}0.92 \\
{[1.06]}\end{array}$ & $\begin{array}{l}0.012 \\
{[0.75]}\end{array}$ & $\begin{array}{l}0.0014 \\
{[0.70]^{\mathrm{a}}}\end{array}$ & $\begin{array}{l}0.0037 \\
{[0.72]}\end{array}$ & - & - & $\begin{array}{c}\text { Numata et } \\
\text { al. (2009) }\end{array}$ \\
\hline Korean & $457 / 386$ & $\begin{array}{c}0.64 \\
{[0.93]} \\
\end{array}$ & $\begin{array}{c}0.06 \\
{[1.24]} \\
\end{array}$ & $\begin{array}{c}0.93 \\
{[0.98]} \\
\end{array}$ & $\begin{array}{c}0.05 \\
{[0.72]^{\mathrm{b}}}\end{array}$ & $\begin{array}{c}0.17 \\
{[0.82]} \\
\end{array}$ & $\begin{array}{c}0.02 \\
{[0.72]} \\
\end{array}$ & $\begin{array}{c}0.03 \\
{[0.64]} \\
\end{array}$ & $\begin{array}{c}0.03 \\
{[0.62]} \\
\end{array}$ & This study \\
\hline \multicolumn{11}{|l|}{ Meta-analysis $^{\mathrm{c}}$} \\
\hline $\begin{array}{l}p \text {-value } \\
\text { (Case/control) }\end{array}$ & & - & - & $\begin{array}{c}0.90 \\
{[1.02]} \\
(901 / 838)\end{array}$ & $\begin{array}{c}\mathbf{0 . 0 0 8 8} \\
{[\mathbf{0 . 7 4}]} \\
(901 / 838) \\
\end{array}$ & $\begin{array}{c}\mathbf{0 . 0 1 9} \\
{[\mathbf{0 . 7 5}]} \\
(901 / 838)\end{array}$ & $\begin{array}{c}\mathbf{0 . 0 0 3 8} \\
{[\mathbf{0 . 7 1}]} \\
(901 / 838) \\
\end{array}$ & - & - & \\
\hline
\end{tabular}

${ }^{a}$ Odds ratio was calculated by each genotypes of cases and controls using a tool in MedCalc (http://www.medcalc.org/calc/odds_ratio. php). ${ }^{\mathrm{b}} p$-value in a dominant model; other $p$-values in a co-dominant model in Korean; ${ }^{\mathrm{c}}$ The meta-analysis performed with Japanese and Korean because other studies were not include enough data to conduct the meta-analysis. The meta-analysis was conducted by PLINK (http://pngu.mgh.harvard.edu/ purcell/plink/metaanal.shtml). Bold values indicate significant differences $(p<0.05)$.

\section{Discussion}

$P D E 4 B$ was evidenced as a considerable causal gene for schizophrenia from the previous observations. Firstly, 1p31.2 translocation directly disrupted $P D E 4 B$ gene, resulting in schizophrenia occurrence (Millar et al. 2005). Secondly, high cAMP level was revealed to be related with behavioral defects (Davis et al. 1995) and human PDE4B plays an important role in cAMP hydrolysis (Uzunov and Weiss 1972). Thirdly, schizophrenia patients had a low expression of PDE4B level compared with healthy control subjects in postmortem brain tissue, which implicates that the dysregulation of PDE4B is associated with schizophrenia (Fatemi et al. 2005, 2008). Fourthly, genetic associations between $P D E 4 B$ polymorphisms and schizophrenia (Fatemi et al. 2008; Numata et al. 2008; Holliday et al. 2009) from different ethnic populations such as Caucasians, African Americans, Indians, and Japanese were reported (Table 4).

The first association study between $P D E 4 B$ polymorphisms and schizophrenia was conducted in Caucasian and African American populations (Fatemi et al. 2008). Among twenty seven variations investigated, they found that two SNPs, $r s 1321177$ and $r s 2144719$, were most significantly associated with schizophrenia in Caucasian $(p=0.0004$ and 0.0006 , respectively). However, in contrast, this association was not detected in African American. It was also observed that three SNPs (rs1040716, rs2180335, and rs472952) and two SNPs ( $r s 11208756$ and rs6700403) were significantly related with schizophrenia in Japanese and Indian populations, respectively (Numata et al. 2008; Holliday et al. 2009). All positive findings indicated that $P D E 4 B$ polymorphisms were significantly associated with the risk of schizophrenia.

In the current study, we conducted a replication study for these positive findings in a Korean population. As a result, we also identified that four SNPs (rs1040716, rs472952, $r s 1321177$, and $r s 2144719)$ showed nominal associations for schizophrenia in a Korean population $(p=0.02 \sim 0.05)$. The $r s 1040716$ polymorphism showed positive associations for schizophrenia among Caucasian, African American, Japanese, and Korean population $(p=0.0031 \sim 0.05)$. In the case of $r s 472952$, Japanese and Korean populations showed significant associations for schizophrenia $(p=0.0037 \sim 0.02)$ (Table 4). In order to assess genetic effect of PDE4B SNPs in all populations, a meta-analysis was conducted. Three SNPs (rs1040716, rs2180335, and rs472952) revealed significant associations in Japanese and Korean populations (meta- $p$ value $=0.0038 \sim 0.019$, odds ratio $=0.71 \sim 0.75)($ Table 4$)$. Among them, rs472952 showed the strongest association with the risk of schizophrenia (meta $p$-value $=0.0038$, odds ratio $=0.71)$.

Since SPEM abnormality is proposed as one of the most consistent neurophysiological endophenotype in schizophrenia, it would be valuable to investigate the genetic effect of the polymorphisms for schizophrenia. In this study, schizophrenia patients were divided into two categories based on SPEM abnormality into good and poor performers. Among eight variations, the $r s 11208756$ polymorphism was revealed to have a nominal association for SPEM abnormality ( $p=$ 
0.05 , odds ratio $=0.48)($ Table 3$)$. Patients with rare allele (C) of the rs11208756 SNP showed a lower frequency in poor group (Ln S/N ratio < 3.97) than good group (Ln S/N ratio $\geq 3.97$ ). It implicates that the rare allele may be a genetic factor for SPEM abnormality. However, since the current study examined the relationship between PDE4B SNPs and SPEM abnormality with small samples, further replication study would be required to further assess the genetic effect of the polymorphisms with a larger cohort. In case of normal healthy subjects, we did not perform association analysis of SPEM function abnormality because there are low incidence of SPEM impairment in healthy subjects $(<10 \%)$.

In summary, we scrutinized the association of $P D E 4 B$ polymorphisms with schizophrenia and SPEM abnormality in a Korean population. Our results in this study replicated the positive associations of $P D E 4 B$ polymorphisms with schizophrenia in other previous studies. We found that three SNPs (rs1040716, rs2180335, and rs472952) revealed significant associations in meta-analysis in Japanese and Korean populations (meta- $p$ value $=0.0038 \sim 0.019$ ). The finding indicates that PDE4B SNPs might be the genetic factor for schizophrenia. Furthermore, we identified a nominal association between SPEM abnormality and schizophrenia in this study. Thus, we provide new evidence from the Korean population for the involvement of $P D E 4 B$ gene in the development of schizophrenia and SPEM abnormality in the disease.

Acknowledgements. This study was supported by a grant of the Korea Healthcare technology R\&D Project, Ministry of Health \& Welfare, Republic of Korea (No. A101023). This research was supported by Basic Science Research Program through the National Research Foundation of Korea (NRF) funded by the Ministry of Education, Science and Technology (No. 2011-0011935) and the Ministry of Education, Science and Technology, Republic of Korea (No. 2009-0093822).

Conflict of interest: The authors declare no conflict of interest.

\section{Supplementary Material}

Table S1. Assay IDs of PDE4B polymorphisms

\begin{tabular}{lc}
\hline SNP name & Assay-on-demand ID \\
\hline$r s 11208756$ & $\mathrm{C} \_31224243 \_10$ \\
$r s 6700403$ & $\mathrm{C} \_$1270990_10 \\
$r s 599381$ & $\mathrm{C} \_$599289_10 \\
$r s 1040716$ & $\mathrm{C} \_$1270948_20 \\
$r s 2180335$ & $\mathrm{C} \_$1270935_10 \\
$r s 472952$ & $\mathrm{C} \_8362833 \_10$ \\
$r s 1321177$ & $\mathrm{C} \_8363076 \_10$ \\
$r s 2144719$ & $\mathrm{C} \_16074734 \_10$ \\
\hline
\end{tabular}

TaqMan assay IDs from Applied Biosystems, CA, USA. SNP, singlenucleotide polymorphism.

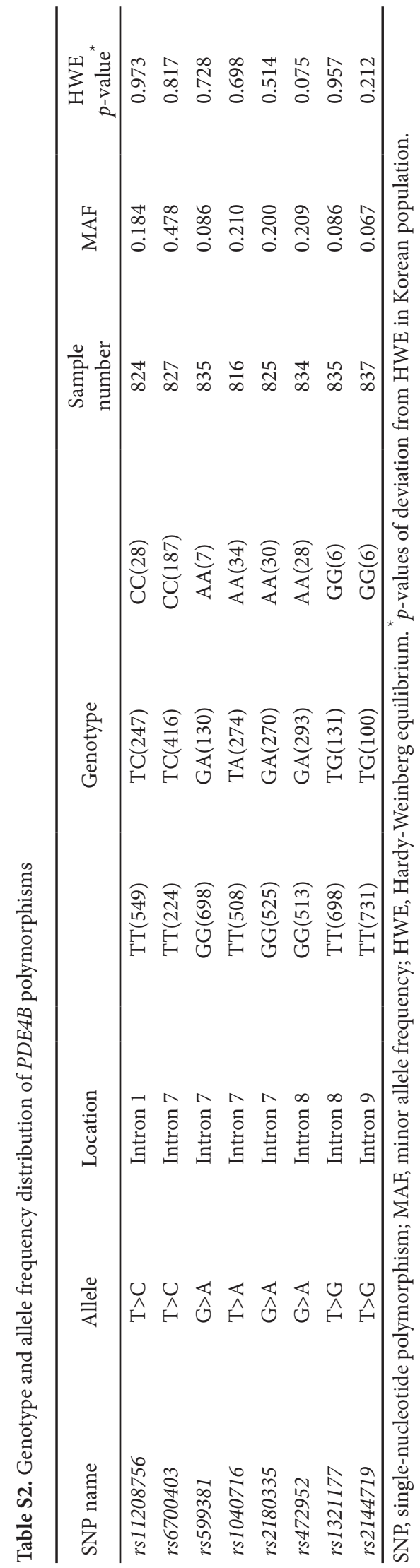




\section{References}

Association (2000): Diagnostic and statistical manual of mental disorders (4th edition). American Psychiatric Association, Arlington, VA, USA

Bae J. S., Pasaje C. F., Park B. L., Cheong H. S., Kim J. H., Kim J. Y., Shin J. G., Park C. S., Kim B. J., Lee C. S., et al. (2012): Genetic association analysis of ERBB4 polymorphisms with the risk of schizophrenia and SPEM abnormality in a Korean population. Brain. Res. 1466, 146-151 http://dx.doi.org/10.1016/j.brainres.2012.05.029

Barrett J. C., Fry B., Maller J., Daly M. J. (2005): Haploview: analysis and visualization of LD and haplotype maps. Bioinformatics 21, 263-265 http://dx.doi.org/10.1093/bioinformatics/bth457

Cardno A. G., Gottesman I. I. (2000): Twin studies of schizophrenia: from bow-and-arrow concordances to star wars $\mathrm{Mx}$ and functional genomics. Am. J. Med. Genet. 97, 12-17 http://dx.doi.org/10.1002/(SICI)1096-8628(200021)97:1<12::AID-AJMG3>3.0.CO;2-U

Chen P. L., Avramopoulos D., Lasseter V. K., McGrath J. A., Fallin M. D., Liang K. Y., Nestadt G., Feng N., Steel G., Cutting A. S., et al. (2009): Fine mapping on chromosome 10q22-q23 implicates Neuregulin 3 in schizophrenia. Am. J. Hum. Genet. 84, 21-34 http://dx.doi.org/10.1016/j.ajhg.2008.12.005

Davis R. L., Cherry J., Dauwalder B., Han P. L., Skoulakis E. (1995): The cyclic AMP system and Drosophila learning. Mol. Cell. Biochem. 149-150, 271-227 http://dx.doi.org/10.1007/BF01076588

Fatemi S. H., King D. P., Reutiman T. J., Folsom T. D., Laurence J. A., Lee S., Fan Y. T., Paciga S. A., Conti M., Menniti F. S. (2008): PDE4B polymorphisms and decreased PDE4B expression are associated with schizophrenia. Schizophr. Res. 101, 36-49 http://dx.doi.org/10.1016/j.schres.2008.01.029

Fatemi S. H., Stary J. M., Earle J. A., Araghi-Niknam M., Eagan E. (2005): GABAergic dysfunction in schizophrenia and mood disorders as reflected by decreased levels of glutamic acid decarboxylase 65 and $67 \mathrm{kDa}$ and Reelin proteins in cerebellum. Schizophr. Res. 72, 109-122 http://dx.doi.org/10.1016/j.schres.2004.02.017

Holliday E. G., Nyholt D. R., Tirupati S., John S., Ramachandran P., Ramamurti M., Ramadoss A. J., Jeyagurunathan A., Kottiswaran S., Smith H. J., et al. (2009): Strong evidence for a novel schizophrenia risk locus on chromosome 1p31.1 in homogeneous pedigrees from Tamil Nadu, India. Am. J. Psychiatry 166, 206-215 http://dx.doi.org/10.1176/appi.ajp.2008.08030442

Houslay M. D. (2010): Underpinning compartmentalised cAMP signalling through targeted cAMP breakdown. Trends Biochem. Sci. 35, 91-100 http://dx.doi.org/10.1016/j.tibs.2009.09.007

Houslay M. D., Adams D. R. (2003): PDE4 cAMP phosphodiesterases: modular enzymes that orchestrate signalling cross-talk, desensitization and compartmentalization. Biochem. J. 370, 1-18 http://dx.doi.org/10.1042/BJ20021698
Kirov G., Ivanov D., Williams N. M., Preece A., Nikolov I., Milev R., Koleva S., Dimitrova A., Toncheva D., O'Donovan M. C., Owen M. J. (2004): Strong evidence for association between the dystrobrevin binding protein 1 gene (DTNBP1) and schizophrenia in 488 parent-offspring trios from Bulgaria. Biol. Psychiatry 55, 971-975 http://dx.doi.org/10.1016/j.biopsych.2004.01.025

Lepagnol-Bestel A. M., Dubertret C., Benmessaoud D., Simonneau M., Ades J., Kacha F., Hamdani N., Gorwood P., Ramoz N. (2010): Association of DISC1 gene with schizophrenia in families from two distinct French and Algerian populations. Psychiatr. Genet. 20, 298-303 http://dx.doi.org/10.1097/YPG.0b013e32833aa5c4

Li D., Collier D. A., He L. (2006): Meta-analysis shows strong positive association of the neuregulin 1 (NRG1) gene with schizophrenia. Hum. Mol. Genet. 15, 1995-2002 http://dx.doi.org/10.1093/hmg/ddl122

Menashe I., Rosenberg P. S., Chen B. E. (2008): PGA: power calculator for case-control genetic association analyses. BMC Genet. 9, 36 http://dx.doi.org/10.1186/1471-2156-9-36

Millar J. K., Wilson-Annan J. C., Anderson S., Christie S., Taylor M. S., Semple C. A., Devon R. S., St Clair D. M., Muir W. J., Blackwood D. H., Porteous D. J. (2000): Disruption of two novel genes by a translocation co-segregating with schizophrenia. Hum. Mol. Genet. 9, 1415-1423 http://dx.doi.org/10.1093/hmg/9.9.1415

Millar J. K., Pickard B. S., Mackie S., James R., Christie S., Buchanan S. R., Malloy M. P., Chubb J. E., Huston E., Baillie G. S., et al. (2005): DISC1 and PDE4B are interacting genetic factors in schizophrenia that regulate cAMP signaling. Science 310, 1187-1191 http://dx.doi.org/10.1126/science.1112915

Numata S., Ueno S., Iga J., Song H., Nakataki M., Tayoshi S., Sumitani S., Tomotake M., Itakura M., Sano A., Ohmori T. (2008): Positive association of the PDE4B (phosphodiesterase 4B) gene with schizophrenia in the Japanese population. J. Psychiatr. Res. 43, 7-12 http://dx.doi.org/10.1016/j.jpsychires.2008.01.013

Silberberg G., Darvasi A., Pinkas-Kramarski R., Navon R. (2006): The involvement of ErbB4 with schizophrenia: association and expression studies. Am. J. Med. Genet. B Neuropsychiatr. Genet. 141B, 142-148 http://dx.doi.org/10.1002/ajmg.b.30275

Stephens M., Smith N. J., Donnelly P. (2001): A new statistical method for haplotype reconstruction from population data. Am. J. Hum. Genet. 68, 978-989 http://dx.doi.org/10.1086/319501

Uzunov P., Weiss B. (1972): Separation of multiple molecular forms of cyclic adenosine-3' $3^{\prime}$ '-monophosphate phosphodiesterase in rat cerebellum by polyacrylamide gel electrophoresis. Biochim. Biophys. Acta 284, 220-226 http://dx.doi.org/10.1016/0005-2744(72)90060-5

Received: August 29, 2014

Final version accepted: February 6, 2015

First published online: April 30, 2015 